\title{
AOR
}

Selected Papers of \#AolR2021:

The 22nd Annual Conference of the

Association of Internet Researchers

Virtual Event / 13-16 Oct 2021

\section{TOP 5 TINDER HACKS! BLACKBOXING ALGORITHMS IN THE DATING APP INDUSTRY}

\author{
David Myles \\ McGill University \\ Martin Blais \\ Université du Québec à Montréal
}

While dating has long been mediated by professional matchmakers and technologies, the past decades have been marked by the ongoing rationalization of matchmaking practices through the use of mathematics (Fry, 2015). Today, mobile dating apps and the algorithms they operate are reconfiguring the matchmaking industry and contemporary dating cultures (Duguay et al., 2017). Tinder's swipe feature - which operates classification and recommendation algorithms that have been likened to the Elo scoring technique - has been particularly influential, giving way to a new generation of dating apps (Ranzini \& Lutz, 2017). In this paper, we argue that the mystique surrounding Tinder's algorithms, that is, their alleged unintelligible nature, is as productive for the matchmaking industry as the actual technical operations they perform.

\section{Algorithmic Blackboxing: Understanding the Discursive Construction of Algorithms}

This paper examines how algorithms are socially and discursively constituted in line with critical algorithm studies (Seaver, 2017). We draw on the notion of 'algorithmic blackboxing' (Bucher, 2018), that is, how actors strategically construct algorithms as black boxes to reach certain goals. As argued by Bucher (2018: 47): "The question is not simply whether we can know algorithms but when the realm of its intelligibility is made more or less probable. That is, when are algorithms framed as unknowns, for whom and for what purpose?" Thus, we are interested in understanding how actors in the dating industry construct matchmaking algorithms as strategic unknowns that can be harnessed to reach commercial objectives. To do so, we collected a corpus of 48 online dating guides that offer 'best advice' to exploit Tinder's matchmaking algorithms. We conducted a discursive analysis from a Foucauldian perspective (Graham, 2011),

Suggested Citation (APA): Myles, D., Blais. M. (2021, October). Top 5 Tinder Hacks! Blackboxing Algorithms in the Dating App Industry. Paper (or panel) presented at AolR 2021: The 22nd Annual Conference of the Association of Internet Researchers. Virtual Event: AolR. Retrieved from http://spir.aoir.org. 
that is, by examining discourses in their propensity to set the possibilities through which social subjects and problems can be constituted. Through our analysis, we sought to understand how these guides construct Tinder's algorithms discursively, under what imperatives, and with what effects.

\section{Hacking Tinder: Becoming Algorithmically Recognizable to Get More Tinder Matches}

The guides we analyzed overwhelmingly construct Tinder's algorithms as black boxes whose secrets must be unlocked for users to generate matches and, therefore, find love. The alleged unintelligibility of Tinder's algorithms allows self-proclaimed 'dating experts' to sell their advice or services in the context of a speculative dating economy. Tinder users are depicted as helpless or clueless when facing the app's 'sophisticated' or 'opaque' algorithms, as well as in dire need of guidance from professionals to mitigate increasing algorithmic speculations. Furthermore, dating guides promote a common injunction to hack Tinder. In this context, the 'hacking' metaphor is not invoked to invite users to divert or hijack the dating app. On the contrary, 'hacks' refer to strategies that insist on the importance for Tinder users to modulate their behaviors and practices in order to become more algorithmically recognizable (Gillespie, 2017). Indeed, the guides we analyzed contend that it is through algorithmic recognition that users can obtain more matches. Thus, while hacks are marketed as tricks to help users make "Tinder's algorithms work for them," we argue that they are more likely making users work for the app's algorithms.

\section{The Pervasion of Dataism in the Matchmaking Industry}

Our analysis also suggests that guides readily invoke rhetorical arguments that draw on statistical data produced by Tinder and the dating experts that work for the company. For example, using a smiling picture would increase your matches by $14 \%$, while wearing sunglasses would reduce your matches by $12 \%$. These arguments are in line with an ideology of dataism (van Dijck, 2014: 198), which constitutes a "widespread belief in the objective quantification and potential tracking of all kinds of human behavior and sociality through online media technologies". We argue that these dating statistics operate an algorithmic recursive loop. Tinder develops non-neutral algorithms that favor certain behaviors and produces data to show how users who follow these rules are rewarded with more matches. Then, users (potentially) modulate their behaviors to become more algorithmically recognizable, which in turn further enacts the app's algorithmic imperatives in a sort of self-fulfilling prophecy. Moreover, we explore how the pervasion of a dataist ideology within the matchmaking industry gives way to new 'regimes of truth' (Foucault, 2012) over matters of love and sexuality that compete against other established regimes (clinical psychology, sexology, evolutionary biology, popular knowledge, etc.). 


\section{Box as Old as Time? Blackboxing Gender on Tinder}

Finally, this paper argues that, while apps respond to new algorithmic imperatives that partly reconfigure contemporary dating cultures, the practice of blackboxing is not new within the matchmaking industry. Romance has long been discursively constructed as mysterious or as a black box to be opened (Luhmann, 1986). Similarly, many self-help books on heterosexual dating have naturalized the idea that men and women are immeasurably opposed, using a form of blackboxing that justifies the multiplication of derivative products promising men and women a better mutual understanding and greater relational success. The best-seller Men Are From Mars, Women Are From Venus (Gray, 1992) is a prime example of this sort of gender blackboxing. To that effect, the guides we analyzed mostly construct relationships through the lens of competition, gamification, or marketing, in ways that reproduce more or less accurate conceptions of gender roles in the context of heterosexual dating, namely, by drawing on pseudo-knowledge from evolutionary biology. Our corpus of guides overwhelmingly identifies its readership as masculine and stresses the importance for 'males' to attract the attention of fleeting 'females'. It depicts Tinder dating as a numbers' game, one where men are expected to modulate their behaviors and where women are understood as 'black boxes' whose mysteries men must unveil by following specific matchmaking advice.

We conclude by underlying how dating guides (just like the matchmaking algorithms they claim to unpack) can reproduce harmful conceptions of intimate relationships that focus on ranking and systematically (de)valuating certain identities. Thus, we advocate for the importance of critically examining the increasing algorithmic mediation of dating cultures at the intersection of Internet, gender, and sexuality studies.

\section{References}

Bucher, T. (2018). If... then: Algorithmic power and politics. Oxford: Oxford University Press.

Duguay, S., Burgess, J., \& Light, B. (2017). Mobile Dating and Hookup App Culture. In Digital Media: Transformations in Human Communication. New York: Peter Lang.

Foucault, M. (2012). Du gouvernement des vivants: cours au Collège de France: 19791980. Paris: Gallimard.

Fry, H. (2015). The Mathematics of Love: Patterns, Proofs, and the Search for the Ultimate Equation. New York: Simon and Schuster.

Gillespie, T. (2017). Algorithmically recognizable: Santorum's Google problem, and Google's Santorum problem. Information, communication \& society, 20(1), 63-80.

Graham, L. J. (2011). Discourse Analysis and the Critical Use of Foucault. Educational Philosophy and Theory, 43(6), 663-674.

Gray, J. (1992). Men are from Mars. Women Are from Venus, New York: Harper Collins. 
Luhmann, N. (1986). Love as Passion: The Codification of Intimacy. Cambridge: Harvard University Press.

Ranzini, G., \& Lutz, C. (2017). Love at first swipe? Explaining Tinder self-presentation and motives. Mobile Media \& Communication, 5(1), 80-101.

Seaver, N. (2017). Algorithms as culture: Some tactics for the ethnography of algorithmic systems. Big Data \& Society, 4(2), 2053951717738104.

van Dijck, J. (2014). Datafication, Dataism and Dataveillance: Big Data Between Scientific Paradigm and Ideology. Surveillance et Society, 12(2), 197-208. doi: $10.24908 /$ ss.v12i 2.4776 